Kotova Nina Sergevna, Doctor of Philology, Prof., Candidate of Philosophical Sciences, Head of Cathedra of Foreign languages and speech communication, South-Russia Institute of Management - branch of Russian Presidential Academy of National Economy and Public Administration (70/54, Pushkinskaya St., Rostov-on-Don, 344002, Russian Federation); Prof. of Cathedra of Educational Psychology, Southern Federal University (105/42, Bolshaya Sadovaya St., Rostov-on-Don, 344006, Russian Federation). E-mail: ninakotova@mail.ru

Gelpey Elena Aleksandrovna, Candidate of Philological Sciences, Associate Prof. of Cathedra of Foreign languages and speech communication, South-Russia Institute of Management - branch of Russian Presidential Academy of National Economy and Public Administration (70/54, Pushkinskaya St., Rostov-on-Don, 344002, Russian Federation). E-mail: mail2003@list.ru

Kotov Grigory Sergeevich, post-graduate at the Academy of Psychology and Pedagogics, Southern Federal University (105/42, Bolshaya Sadovaya St., Rostov-on-Don, 344002, Russian Federation). E-mail: Alamorf@yandex.ru

\title{
CRITICAL THINKING AS AN ESSENTIAL COMPETENCE FOR TRAINING TODAYS MANAGERIAL STAFF
}

\section{Abstract}

Forming and developing critical thinking skill is a fundamental requirement to education in the modern world. This skill is essential for training managers with out- of- the -box thinking, who are capable of acting promptly, analyzing, predicting problems and taking correct decisions. It's critical thinking, which helps employees to be in demand on the labour market. The authors look at the need of Russian higher educational institutions in systematic, interdisciplinary approach to the formation and development of critical thinking on the example of RANEPA students and teachers.

Keywords: critical thinking, managerial staff, interdisciplinary approach, skill, competence, employment, employers, intellectual processes, field of business.

\section{МЕХАНИЗМЫ ДОСТИЖЕНИЯ УПРАВЛЕНЧЕСКОГО РЕЗОНАНСА В СИСТЕМЕ ВЗАИМОДЕЙСТВИЙ УЧАСТНИКОВ ПРОЦЕССА СОЗДАНИЯ ДОБАВОЧНОЙ СТОИМОСТИ В НЕФТЯНОЙ ОТРАСЛИ}

\author{
Маркин \\ олег \\ кандидат экономических наук, директор по развитию, 000 "Юг Регион \\ Олег \\ Трейдинг" (344006, Россия, г. Ростов-на-Дону, ул. Пушкинская, 144). \\ Владимирович \\ E-mail: ovmarkin@tnk-bp.com.
}

\section{Аннотация}

В статье рассматривается проблема достижения управленческого резонанса в рамках инновационного взаимодействия участников единого замкнутого технологического цикла по созданию добавочной стоимости в нефтяной отрасли - от добычи нефти до этапа доставки продуктов ее переработки конечному потребителю. Основное внимание уделяется согласованию разнонаправленных интересов участников на каждом этапе технологической цепи (добыча нефти, транспортировка нефти, переработка нефти, транспортировка и реализация нефтепродуктов и т.д.), поскольку нахождение баланса указанных интересов является главным фактором эффективности всего процесса взаимодействия и достижения управленческого консенсуса в вопросах внедрения инноваций на всех этапах. Приведена примерная модель гармонизации управленческих решений, принимаемых участниками технологического взаимодействия в нефтяной отрасли, направленных на рост эффективности использования их потенциала.

Ключевые слова: управленческий резонанс, участники технологического взаимодействия, нефтяная отрасль, баланс интересов, процесс создания добавочной стоимости, нефтегазовый комплекс, инновационные процессы, биржевой рынок, внедрение инноваций.

В контексте императивов общенациональной модернизации наиболее ярко проблемы недоиспользования потенциала инноваций высвечиваются в базовых секторах экономики, в числе которых - нефтяная отрасль. Российский опыт убедительно верифицирует тот факт, что в нефтегазовом комплексе в целом и в его отраслевых составляющих существуют значительные проблемы, препятствующие модернизации, среди которых - не только неэффективность системы лицензирования, налогообложения, воспроизводства и охраны сырьевой базы отрасли, но также недостаточный уровень использования управленческого потенциала в рамках взаимодействия участников процесса создания добавочной стоимости. Складывающаяся в последние годы динамика экономических и производственных показателей отрасли свидетельствует о необходимости более эффективного использовании возможностей нефтедобывающих компаний и нефтеперерабатывающих предприятий несмотря на значительный рост связанных с этим экономических, инвестиционных, политических, экологических и других рисков. В этой связи возникает насущная необходимость в совершенствовании управления взаимодействием крупных компаний и предприятий нефтяной отрасли с использованием нового и адаптацией существующего инструментария управления указанным взаимодействием. Иными словами - достижения управленческого резонанса на всех этапах технологической цепи [4].

При этом следует отметить, что несмотря на большое количество публикаций в рамках очерченной проблематики [1, 2, 5-12], отсутствует целостная концептуальная разработка теоретикометодологических и практических вопросов, связанных с разработкой такого рода инструментария организации и управления хозяйственными образованиями в нефтяной отрасли в процессе технологического взаимодействия их участников, адаптированного к меняющимся экономическим условиям, в том числе мировым (продолжающиеся санкции). 
Постоянно существующая угроза возникновения новых или усиления уже действующих санкций дает дополнительный толчок к использованию более совершенных технологий управления нефтяными компаниями, активизации инновационных процессов на всех технологических этапах в отрасли, повышению роли импортозамещения [3]. Такие действия важны в особенно чувствительных для стратегических интересов страны областях, в числе которых - нефтяная отрасль. Необходимо заметить, что американские ограничения являются большее жесткими по сравнению с Евросоюзом, запретившим поставки в Россию технологий для глубинной добычи нефти, освоения арктического шельфа и разработки сланцевых нефтяных запасов.

Для решения проблем, сопряженных с негативным действием санкций, Министерство финансов России совершенствует налоговую реформу (в части пошлин на экспорт нефти, акцизов на нефтепродукты, компенсации повышения НДПИ и др.), а также проводит адаптивную финансовоэкономическую политику, формируя тем самым пакет макроэкономических детерминант для менеджмента компаний и их подразделений - участников единой технологической цепи. Только при таком грамотном и эффективном управлении нефтяным сектором российской экономики возможно не только нивелирование негативных последствий экономической санкций, но также наращивание потенциала отрасли и получение определенных выгод.

Рассматривая проблему достижения управленческого резонанса на всех этапах технологического взаимодействия участников процесса получения добавочной стоимости, важно учитывать действующую в каждый конкретный период времени методологию формирования цен, поскольку несмотря на общепринятые методы расчета цены н нефть и нефтепродукты, у каждого участника она может существенно отличающейся. Именно это обстоятельство является основным источником противоречивости и несогласованности интересов участников единой технологической цепи.

Поэтому только с 1986 г. стал на самом деле работать конкурентный принцип ценообразования. Непрозрачность нефтяного рынка является одной из важнейших проблем его ценообразования, что отражается и на деятельности менеджмента российских нефтяных компаний. Это имеет отношение в первую очередь к оценке базовых факторов - зависимости спроса и предложения, а также внебиржевых цен на нефть.

Создание эффективных инструментов хеджирования декларируется одной из первоочередных целей развития биржевого рынка деривативов. Помимо этого, одной из особенностей менталитета менеджеров нефтяных компаний является то, что под фактором риска они, как правило, подразумевают не всякое изменение цен (волатильность), а только ведущее к расходам. Значительное число независимых исследований в итоге выявляет, что производители хеджируют лишь несущественную часть своих рисков, коррелирующих с изменениями цен на нефть.

В нефтяной отрасли, как и во всех других, инновационные решения повышают эффективность работы компании на всех стадиях производства, начиная от добычи нефти и заканчивая реализацией нефтепродуктов. В условиях активного перехода российской экономики на инновационный путь развития и ухода от сырьевой модели, необходим соответствующий «инновационный» скачок именно в нефтегазовой отрасли.

В планах российского руководства намечена целевая поддержка инновационной деятельности компаний нефтяного сектора. По мнению руководителей крупных российских нефтяных компаний, проблема данного сектора находится в плоскости налоговой политики государства и расходов на НИОКР, а не дефицита идей или возможностей их осуществления. Законы не разрешают полностью учитывать расходы на НИОКР, а также информационные и консультационные услуги научно-технического характера при расчете налога на прибыль.

Основные мероприятия в рамках модернизации нефтяной отрасли на основе внедрения инноваций:

- преодоление спада и обеспечение умеренного роста добычи (производства) энергетических ресурсов при увеличении эффективности их использования за счет внедрения новейших технологий;

- увеличение глубины и эффективности переработки нефти с использованием новых технологий;

- использование экологически чистых технологий, достижение экологической приемлемости действующих и строящихся объектов нефтегазовой промышленности и энергопотребляющих установок;

- создание надежной сырьевой базы и обеспечение устойчивого развития нефтяного комплекса в условиях формирования рыночных отношений;

- энергосбережение и повышение эффективности использования топливно-энергетических ресурсов.

Результаты проведенного анализа позволили сделать вывод о том, что традиционные российские ВИНК работают не в полной мере на экономику страны, несмотря на их значительные конкурентные преимущества. В этой связи автором проводилось сравнение кластерного образования и 
компаний с вертикальной интеграцией с учетом того, что нефтяным кластерам присущи достоинства ВИНК, кроме того, такая форма интеграции имеет меньше недостатков.

Основные преимущества кластерной организации технологического взаимодействия участников по сравнению с ВИНК состоят в следующем.

Каждый участник кластера (как правило, это субъект определенного этапа технологической цепи создания добавочной стоимости), с одной стороны, обладает определенной самостоятельностью (в том числе юридической), с другой, является членом системы синергетических отношений в кластере, имея возможность получать значительно больший экономический эффект по сравнению с вариантом самостоятельного функционирования.

Как показывает мировой и российский опыт, кластерная модель технологического взаимодействия участников нефтяной отрасли повышает масштабы внедрения инноваций, в том числе управленческих, что дает возможность укреплять конкурентные позиции отрасли (компании) на мировом рынке. Кластеры могут расширяться, формироваться и углубляться при различных изменениях внешней среды, но при неблагоприятных условиях возможен процесс распада и свертывания таких структур.

Высокий инновационный потенциал кластера позволяет существенно сократить совокупные и индивидуальные (отдельных участников кластера) затраты на разработку и коммерциализацию новшеств (продуктовых, технологических и управленческих) благодаря эффективной производственнотехнологической структуре кластера и возможности достижения управленческого резонанса во всех его звеньях. Существуют две модели создания инновационно-ориентированного нефтяного кластера.

Первая модель базируется на идее создания вертикально-интегрированной структуры и ориентирована на задействование ресурсного потенциала уже функционирующей ВИНК, в которую входят как профильные, так и непрофильные (вспомогательные, обслуживающие) предприятия. Данная модель кластеризации ориентирована, во-первых, на существенный рост эффективности функционирования нефтяной отрасли и региона (регионов) локализации деятельности кластера; во-вторых, на скорейшую адаптацию участников кластера к нестабильным факторам внешнего окружения и национальным императивам.

Вторая модель кластеризации в нефтяной сфере - это формирование производственноинновационного кластера, в рамках которого взаимодействие участников отдельных этапов технологической цепи создания добавочной стоимости осуществляется по принципу вертикальных (цепь покупок и продаж) и горизонтальных связей (трансфер новых технологий добычи нефти, ее транспортировки, переработки, хранения, реализации нефтепродуктов и др.). Именно «взаимодействие внутри инновационного кластера, способность его участников эффективно использовать внутренние и мобилизовать внешние ресурсы влияет на его конкурентоспособность на внутреннем и внешнем рынках. В эффективно функционирующих инновационных кластерах ускоряется инновационный процесс, а у участников кластера развиваются такие преимущества, как восприимчивость к инновациям, рационализация бизнеса, опережающий рост производительности и т.д.» [5].

Основной целью системы межкластерного информационного воздействия выступает повышение уровня инновационности действующих хозяйствующих субъектов, а также их инновационнотехнологической сбалансированности, достижение управленческого резонанса и синергетического эффекта, который возникает в процессе их взаимодействия. Для повышения эффективности взаимодействия участников важно использовать потенциал единого информационного пространства кластера.

В последние годы происходит движение от коммодитизации к дальнейшей финансиализации рынка нефти. Образованы глобальные институты бумажного рынка нефти, возник целый спектр финансовых продуктов и т.п. Все это послужило тому, что сырая нефть из материального товара превращается в глобальный финансовый актив. Цены определяются за пределами собственно нефтяного рынка за счет горизонтальных перетоков огромных масс ликвидных финансовых ресурсов между разными секторами рынка, частью которого стал рынок бумажной нефти.

Таким образом, нефтегазовый комплекс России имеет все необходимые ресурсы для обеспечения высокой конкурентоспособности на мировом рынке. Но чтобы эта ситуация был стабильной, необходимы усилия как со стороны нефтяных компаний, так и государства.

\section{Литература}

1. Балашова E.C., Гнездилова О.И. Совершенствование нормативно-правового обеспечения науки и промышленности как определяющее условие реализации инновационного сценария развития России // Вестник Пермского университета. Серия: Экономика. 2017. Т. 12. № 2. С. 263 - 278.

2. Дорошенко Ю.А., Сомина И.В. Оценка трендов и структурных гармоний инвестиционного обеспечения инновационной деятельности малых предприятий России // Креативная экономика. 2015. Т. 9. № 4. С. $461-472$.

3. Маркин O.B. Инновации в нефтяном секторе российской экономики: практика, факторы развития, перспективы // Гуманитарные и социально-экономические науки. СКНЦ ВШ ЮФУ. 2010. № 6. С. 152 - 156. 
4. Матвеева Л.Г., Маркин О.В. Организационные и управленческие решения в нефтяном комплексе России в условиях модернизации. Монография. Ростов н/Д.: Изд-во ЮФУ, 2011.

5. Прогнозирование, планирование и моделирование: междисциплинарный подход и конвергенция знаний. Коллективная монография. Самара: 000 «Офорт», НОУ ВПО «Самарский институт - Высшая школа приватизации и предпринимательства». 2015.

6. Технологии и инструменты эффективного использования ресурсного потенциала промышленности. Коллективная монография / Под ред. Л.Г. Матвеевой, А.Ю. Никитаевой. Ростов-на-Дону-Таганрог: Изд-во Южного федерального университета, 2016. 190 с.

7. Чернова O.A., Иванов А.В. Модели интеграционного сотрудничества промышленных предприятий: возможности роста капитализации // Инженерный вестник Дона. 2015. Т. 34. № 1-2. С. 27 - 33.

8. Чернова O.A. Оценка целесообразности импортозамещения в производственно-технологических цепочках // Известия Дальневосточного федерального университета. Экономика и управление. 2018. № 1 (85). C. 112 - 123.

9. Balashova E.S., Gromova E.A. Agile manufacturing as a promising concept for Russian industry // IOP Conference Series: Materials Science and Engineering. 2018. 393(1),012095.

10.Balashova E., Gromova E. Russian industrial sector in the conditions of the Fourth Industrial Revolution // IOP Conference Series: Materials Science and Engineering. 2018. 404(1),012014.

11.Doroshenko Y.A., Malykhina I.O., Somina I.V. Studying the mechanism of infrastructure support of high-tech business as an integrator of innovation-investment development // Espacios. 2018. 39(47).

12.Doroshenko, Y.A., Malykhina, I.O., Somina, I.V. Problems and prospects of scaling of high-tech-business as an innovativeinvestment driver of economic systems development // Espacios. 2018. 39(47).

Markin Oleg Vladimirovich, Candidate of Economic Science, Director on Development, LLC "South Region trading" (144, Pushkinskaya str., Rostov-on-Don, 344006, Russian Federation). E-mail: ovmarkin@tnk-bp.com MECHANISMS FOR ACHIEVING MANAGERIAL RESONANCE IN THE FRAMEWORK OF INTERACTION BETWEEN PARTICIPANTS IN THE PROCESS OF CREATING ADDED VALUE IN THE OIL INDUSTRY

\section{Abstract}

The article deals with the problem of achieving managerial resonance in the framework of innovative interaction of participants of a single closed technological cycle to create added value in the oil industry - from oil production to the stage of delivery of products of its processing to the final consumer. Focuses on reconciling divergent interests of participants at each stage of technological chain (oil production, oil transportation, oil refining, transportation and marketing of petroleum products, etc.), since the balance of these interests is a major factor in the effectiveness of the whole process of interaction and achieve managerial consensus in the implementation of innovations at all stages. An approximate model of harmonization of management decisions taken by participants of technological interaction in the oil industry, aimed at increasing the efficiency of their potential.

Keywords: employment management resonance, participants of technological interaction, oil industry, balance of interests, process of creation of additional value, oil and gas complex, innovative processes, stock exchange market, innovation introduction, employers, intellectual processes, sphere of activity.

\section{References}

1. Balashova E.S., Gnezdilova O.I. Sovershenstvovanie normativno-pravovogo obespecheniya nauki i promyshlennosti kak opredelyayushchee uslovie realizacii innovacionnogo scenariya razvitiya Rossii // Vestnik Permskogo universiteta. Seriya: Ekonomika. 2017. T. 12. № 2. P. 263 - 278.

2. Doroshenko YU.A., Somina I.V. Ocenka trendov i strukturnyh garmonij investicionnogo obespecheniya innovacionnoj deyatel'nosti malyh predpriyatij Rossii // Kreativnaya ekonomika. 2015. T. 9. № 4. P. 461 - 472.

3. Markin O.V. Innovacii v neftyanom sektore rossijskoj ekonomiki: praktika, faktory razvitiya, perspektivy // Gumanitarnye i social'no-ekonomicheskie nauki. SKNC VSH YUFU. 2010. № 6. P. 152 - 156.

4. Matveeva L.G., Markin O.V. Organizacionnye i upravlencheskie resheniya v neftyanom komplekse Rossii v usloviyah modernizacii. Monografiya. Rostov n/D.: Izd-vo YUFU, 2011.

5. Prognozirovanie, planirovanie i modelirovanie: mezhdisciplinarnyj podhod i konvergenciya znanij. Kollektivnaya monografiya. Samara: 000 «Ofort», NOU VPO «Samarskij institut - Vysshaya shkola privatizacii i predprinimatel'stva». 2015.

6. Tekhnologii i instrumenty effektivnogo ispol'zovaniya resursnogo potenciala promyshlennosti. Kollektivnaya monografiya / Pod red. L.G.Matveevoj, A.YU.Nikitaevoj. Rostov-na-Donu-Taganrog: Izd-vo YUzhnogo federal'nogo universiteta, 2016. $190 \mathrm{p}$.

7. CHernova O.A., Ivanov A.V. Modeli integracionnogo sotrudnichestva promyshlennyh predpriyatij: vozmozhnosti rosta kapitalizacii // Inzhenernyj vestnik Dona. 2015. T. 34. № 1-2. P. 27 - 33.

8. CHernova O.A. Ocenka celesoobraznosti importozameshcheniya v proizvodstvenno-tekhnologicheskih ce-pochkah // Izvestiya Dal'nevostochnogo federal'nogo universiteta. Ekonomika i upravlenie. 2018. № 1 (85). P. 112 - 123.

9. Balashova E.S., Gromova E.A. Agile manufacturing as a promising concept for Russian industry // IOP Conference Series: Materials Science and Engineering. 2018. 393(1), 012095.

10. Balashova E., Gromova E. Russian industrial sector in the conditions of the Fourth Industrial Revolution // IOP Conference Series: Materials Science and Engineering. 2018. 404(1), 012014.

11. Doroshenko Y.A., Malykhina I.O., Somina I.V. Studying the mechanism of infrastructure support of high-tech business as an integrator of innovation-investment development // Espacios. 2018. 39(47).

12. Doroshenko, Y.A., Malykhina, I.O., Somina, I.V. Problems and prospects of scaling of high-tech-business as an innovativeinvestment driver of economic systems development // Espacios. 2018. 39(47). 